\title{
Pulmonary hypoplasia
}

Pulmonary hypoplasia is common in the perinatal period and a significant cause of death in newborn infants. Wigglesworth and Desai reported an incidence of $14.5 \%$ in a series of perinatal necropsies. ${ }^{1}$ Renal or urinary tract anomalies were the most common associated abnormalities followed by diaphragmatic hernia or eventration. Other associations included skeletal muscle disorders, exomphalos, skeletal dysplasia, hydrops fetalis, trisomy 18, prolonged rupture of the membranes, intrauterine hypoxicischaemic brain damage, and five cases where there was evidence only of intrauterine or intrapartum hypoxia. Husain and Hessel found that $26 \%$ of fetuses, babies, and infants (18 weeks of gestation to 2 years of age) had pulmonary hypoplasia at necropsy, and in this series pulmonary hypoplasia was considered to be the immediate cause of death in $22 \% .^{2}$ In this study diaphragmatic hernia was the most common associated abnormality followed by prolonged rupture of the membranes, renal disorders, hydrops fetalis and chromosomal abnormality.

\section{Aetiology and pathogenesis}

In most cases pulmonary hypoplasia is secondary to an underlying abnormality. The pathogenesis of pulmonary hypoplasia is not fully understood but a normal thoracic cavity, fetal breathing movements, fetal lung liquid at positive pressure, and normal amniotic fluid volume are all required for normal lung growth in utero. Underlying abnormalities that may result in pulmonary hypoplasia can therefore be divided into:

- space occupying lesions in the chest, such as misplaced abdominal organs in congenital diaphragmatic hernia $(\mathrm{CDH})$, congenital cystic adenomatoid malformation (CCAM), and pleural effusions;

- malformations of the chest wall resulting in a small thoracic cavity, as may occur in kyphoscoliosis and some skeletal dysplasias;

- oligohydramnios which may result from lack of functioning renal tissue (bilateral renal agenesis or cystic dysplasia), urinary outflow obstruction, or prolonged premature rupture of the membranes;

- neuromuscular disorders which prevent normal fetal breathing movements.

Primary pulmonary hypoplasia is very rare, but occasionally structurally normal but hypoplastic lungs are found at necropsy and no underlying cause can be identified. Congenital acinar dysplasia is an extremely rare primary maldevelopment of the lungs that results in pulmonary hypoplasia. Pulmonary hypoplasia may also be a feature of trisomy 21 .

\section{Pathology}

Hypoplastic lungs have a decreased number of airway generations, with fewer and smaller peripheral airspaces than normal. Wigglesworth et al ${ }^{\beta}$ reported that lungs which are hypoplastic as a result of oligohydramnios are also structurally and biochemically immature for gestational age. The peripheral parts of the acinus have failed to grow and mature, there are delays in the development of the blood-air barrier, in epithelial maturation, lack of elastic tissue development and low concentrations of lung phospholipids. In contrast, lungs that are hypoplastic from all causes other than oligohydramnios usually have a structure that is appropriate for gestational age. The authors suggest that the maturation arrest, which occurs with pulmonary hypoplasia due to oligohydramnios, may be specifically related to failure to retain fetal lung liquid. However, other studies have shown no difference in the structure and maturity of hypoplastic lungs secondary to renal agenesis or dysplasia, compared with those associated with other types of malformations. ${ }^{45}$ In pulmonary hypoplasia due to congenital acinar dysplasia, the lungs show normal bronchial development but each lobule consists of a terminal bronchiole-like structure from which there are multiple cystic outpouchings lined by a bronchial type of epithelium, but no alveoli. This seems to be a primary maldevelopment of the lungs. ${ }^{6}$

The pulmonary hypoplasia associated with trisomy 21 is due to reduced numbers of alveoli and a smaller alveolar surface area. ${ }^{7}$

\section{Management}

In many of the conditions associated with pulmonary hypoplasia, the underlying abnormality is so severe that survival would not be possible even if the pulmonary hypoplasia could be corrected. However, there are some situations where pulmonary hypoplasia is the only abnormality-for example, when it is secondary to oligohydramnios due to prolonged premature rupture of the membranes, or where the underlying malformation may be amenable to surgical correction, such as congenital diaphragmatic hernia $(\mathrm{CDH})$. Current management relies on removal of a space occupying lesion, if one is present, and supportive care aimed at maintaining adequate oxygenation while pulmonary growth occurs. Despite the use of new technology, such as extra corporeal membrane oxygenation (ECMO) and new drugs, such as nitric oxide, there has been little improvement in the outcome for these infants. CDH is the most common malformation associated with pulmonary hypoplasia and paediatric surgeons have long been frustrated by the poor results following surgery; these are frequently attributable to pulmonary hypoplasia rather than the hernia itself. Attempts have therefore been made recently to correct pulmonary hypoplasia in utero, in the hope of improving the overall prognosis.

\section{Experimental tracheal ligation}

Obstruction of the upper respiratory tract, such as occurs in laryngeal atresia, results in larger than normal lungs. This was confirmed by Carmel et al, who ligated the trachea of fetal rabbits to show that the lungs produce liquid that is independent of the amniotic fluid. As an incidental finding the authors also noted a substantial increase in the size of the lungs following tracheal ligation. ${ }^{8}$ Similar experiments have been done since, predominantly on fetal sheep, and these have shown that tracheal ligation results in dramatic growth of hypoplastic lungs. They have also shown that when the hypoplasia is secondary to surgi- 
cally produced diaphragmatic hernia the lung growth is sufficient to return the abdominal organs (stomach, intestines, and spleen) to the abdominal cavity. ${ }^{9} 10$

Descriptions of the histology and morphometry of the lungs following tracheal ligation vary. In all cases the lungs are larger than those of controls, with increased DNA but normal DNA:total protein ratio, indicating that the increased size is due, at least in part, to cellular proliferation. Some studies describe the lung histology as normal ${ }^{9}$; others report slight increases in alveolar size and number, ${ }^{11}{ }^{12}$ but all describe the lungs as being morphologically mature with thin alveolar septa, when compared with controls. Assessment of the vascular tree has shown that the total number of pulmonary capillaries and larger vessels is greater in fetuses with $\mathrm{CDH}$ and tracheal ligation than in those with $\mathrm{CDH}$ alone, or controls, but because of the increased size of the lungs in the animals with tracheal ligation, the number of vessels per unit area of lung was the same in all three groups. ${ }^{13}$ Animals with $\mathrm{CDH}$ alone also had three times as many fully muscularised vessels as those with $\mathrm{CDH}$ and tracheal ligation, and twice as many as those of the controls. Sylvester reported that tracheal occlusion reverses the high impedance flow normally seen in the pulmonary circulation in association with $\mathrm{CDH}$ and returns the physiological response to oxygen at term to normal. ${ }^{14}$

Assessment of lung function is less reassuring. One study showed normal total lung capacity but decreased functional residual capacity and decreased lung compliance. ${ }^{15}$ Some fetal sheep have been ventilated for 1-2 hours after delivery and achieved oxygenation comparable with that of the controls, but there are no reports of ventilation for a longer time. ${ }^{9}{ }^{10}$ In another study neither of two fetal sheep could maintain adequate oxygenation with unsupported respiration following tracheal occlusion in utero and removal of the plug after delivery. ${ }^{16}$

Biochemical analyses have shown that tracheal ligation does not increase biochemical maturity. ${ }^{10}$ There is a decreased amount of total phospholipid, including phosphotidylcholine which is the most active component of surfactant, and concentrations were lower than in control animals with $\mathrm{CDH}$ but without tracheal ligation - that is, tracheal ligation has an adverse effect on surfactant concentrations. ${ }^{15}$ The decreased surfactant concentrations are caused by decreased numbers, and degeneration of, type 2 pneumocytes. ${ }^{17}$ In a study by O'Toole this was corrected by the administration of exogenous surfactant. ${ }^{18}$ The loss of type 2 pneumocytes depends on the length of time that the trachea is ligated, and de Paepe has shown that tracheal occlusion for more than two weeks results in a clinically significant reduction in the surfactant system, and that by six weeks after ligation type 2 pneumocytes are irreversibly damaged. ${ }^{17}$ Piedboeuf showed that the density of cells expressing surfactant protein C substantially decreases, even one week after tracheal ligation, ${ }^{19}$ although temporary plugging of the trachea for 15 days, followed by a period with a patent trachea before delivery in fetal sheep with normal sized lungs, showed that the density of type 2 pneumocytes was normal at term. ${ }^{20}$ On the other hand, the trachea needs to be occluded long enough for lung growth to occur. In human fetuses it was about one week between the tracheal occlusion and the identification of lung growth, as determined by ultrasound scan. The gestation at which tracheal ligation is performed may also be important. A study by Keramidaris showed that lung growth was greater at a later gestation than an earlier one in fetal sheep, possibly due to the greater accumulation of lung liquid in older fetuses. ${ }^{21}$

The mechanism by which tracheal ligation causes lung growth has not yet been fully elucidated, but it is not sim- ply the result of increased pressure by the lung liquid. Papadakis et al have shown that replacement of lung liquid by saline following tracheal ligation prevents the lung growth normally seen in this situation, indicating that growth factors in the lung liquid have a crucial role. ${ }^{22}$ The growth factors involved are not fully evaluated but include insulin-like growth factor $1,{ }^{23}$ insulin-like growth factor $2,{ }^{24}$ and epidermal growth factor. ${ }^{25}$

\section{Tracheal occlusion for pulmonary hypoplasia associated with CDH}

Despite the problems encountered with tracheal ligation in experimental animals, it has been used in humans to treat $\mathrm{CDH}$ with pulmonary hypoplasia, and this has involved the development of a reversible method of obstructing the trachea. Initially, a foam plug was inserted into the trachea using an endoscopic technique which also had the advantage that a hysterotomy was not required, theoretically reducing the risk of preterm labour. However, this produced extensive tracheal damage. Subsequently, a clip was used which did not seem to damage the trachea, but there are no long term survivors to verify this. The other practical problem is that of in utero surgery, predominantly the prevention of preterm labour. A study by Harrison reports on eight human fetuses who were operated on in the late second trimester. ${ }^{26}$ In two, the lungs did not grow, presumably because the trachea was not completely occluded. There was one death in utero four weeks after the trachea had been clipped, and one fetus aborted eight hours after surgery. One baby developed a severe intraventricular haemorrhage, which led to hydrocephalus, and died when support was withdrawn. Three babies were delivered alive long enough after tracheal obstruction for their lungs to have grown, and they had their CDH repaired. Of these, one initially did well but died from postoperative complications following a Nissan fundoplication for recurrent aspiration pneumonia at 4 months of age. Another had his $\mathrm{CDH}$ repaired at 5 weeks of age, required three months of ventilatory support including ECMO, underwent a fundoplication for gastrooesophageal reflux, and was eventually weaned to nasal oxygen. However, a magnetic resonance imaging scan showed cerebral atrophy and poor myelination, presumed secondary to prolonged intensive care, and he died when support was withdrawn. Both of these babies are reported to have had normal lungs at necropsy, but no detailed description is provided. The one long term survivor required tracheal stenting for two months for tracheomalacia caused by the tracheal plug, and despite some periventricular leucomalacia, was described as doing well at the age of 18 months.

There is also a report of the use of tracheal occlusion with a clip to correct pulmonary hypoplasia associated with a right sided diaphragmatic hernia. The clip was applied using open hysterotomy at 27 weeks of gestation and the baby was delivered at 32 weeks by elective caesarean section. The hernia was repaired and the baby was extubated when 2 weeks old. He was doing well at 4 months of age. ${ }^{27}$ Another baby had a tracheal clip applied endoscopically at 29 weeks of gestation. Premature rupture of the membranes occurred at 33 weeks and the baby was delivered. He was described as having good respiratory function, although there was still some mediastinal shift, but lethal pterygium syndrome was diagnosed and support withdrawn. ${ }^{28}$

A serious complication of tracheal occlusion is hydrops fetalis. ${ }^{29}$ Hydrops has not been described in experimental animals following tracheal ligation and this is thought to have been due to the fact that the enlarged lung can extend through the diaphragmatic defect, so preventing cardiac 
compression and reduced venous return. A baby had open fetal surgery at 26 weeks of gestation, with the trachea being occluded in utero with metal clips. Over the next nine days there was rapid lung expansion and the development of hydrops fetalis. After delivery by caesarean section a laparotomy was performed and a segment of liver, filling the diaphragmatic defect and incarcerated along the mediastinal border, was reduced. The baby continued to require considerable respiratory support and died aged 13 days during a difficult re-intubation.

The survival rate for $\mathrm{CDH}$ with surgical correction in the neonatal period is $65 \%$ (range $44-78 \%$ ) in the latest series, which all come from centres using $\mathrm{ECMO},{ }^{30}$ and therefore only two survivors out of 11 attempts at in utero fetal tracheal obstruction does not compare well. Open fetal repair of $\mathrm{CDH}$ has resulted in a $29 \%$ success rate in 14 patients. ${ }^{31}$

Long term chronic pulmonary morbidity related to pulmonary hypoplasia is beginning to appear, because ECMO has allowed infants to be treated who would previously have died. Some now survive dependent on mechanical ventilation and it has been suggested that fetal treatment with tracheal occlusion might prevent this. ${ }^{29}$ Further elucidation of the pathophysiology of tracheal occlusion is required before its widespread clinical application. If the mechanism by which tracheal occlusion effected pulmonary growth were better understood, it might be possible to avoid tracheal occlusion and instead act directly on the regulatory mechanisms to reverse or prevent pulmonary hypoplasia.

Department of Paediatric Pathology

St Michael's Hospital

Southwell Street

Bristol BS2 8EG

1 Wigglesworth JS, Desai R. Is fetal respiratory function a major determinant of perinatal survival? Lancet 1982;i:264-7.

2 Husain AN, Hessel RG. Neonatal pulmonary hypoplasia: An autopsy study of 25 cases. Pediatr Pathol 1993;13:475-84.

3 Wigglesworth JS, Desai R, Guerrini P. Fetal lung hypoplasia: biochemical and structural variations and their possible significance. Arch Dis Child 1981;56:606-15.

4 Hislop A, Hey E, Reid L. The lungs in congenital bilateral renal agenesis and dysplasia. Arch Dis Child 1979;54:32-8.

5 Reale FR, Esterly JR. Pulmonary hypoplasia: A morphometric study of the lungs of infants with diaphragmatic hernia, anencephaly and renal malformations. Pediatrics 1973;51:91-6.

6 Rutledge JC, Jensen P. Acinar dysplasia:a new form of pulmonary maldevelopment. Hum Pathol 1986;17:1290-3.

7 Cooney TP, Thurlbeck WM. Pulmonary hypoplasia in Down's syndrome. N Engl f Med 1982;307:1170-3.

8 Carmel JA, Friedman F, Adams FH. Fetal tracheal ligation and lung development. Am f Dis Child 1965;109:452-6.

9 DiFiore JW, Fauza DO, Slavin R, Peters CA, Fackler JC, Wilson JM Experimental fetal tracheal ligation reverses the structural and physiologi- cal effects of pulmonary hypoplasia in congenital diaphragmatic hernia. $\mathcal{F}$ ;29:248-57

10 Hedrick MH, Estes JM, Sullivan KM, et al. Plug the lung until it grows (PLUG): A new method to treat congenital diphragmatic hernia in utero. f Pediatr Surg 1994;29:612-17.

11 Wilson JM, DiFiore JW, Peters CA. Experimental fetal tracheal ligation prevents the pulmonary hypoplasia associated with fetal nephrectomy: Possible application for congenital diaphragmatic hernia. 7 Pediatr Surg 1993;28:1433-40.

12 Hashim E, Laberge J-M, Chen M-F, Quillen EW. Reversible tracheal obstruction in the fetal sheep: effects on tracheal fluid pressure and lung obstruction in the fetal sheep: effects o.
growth. F Pediatr Surg 1995;30:1172-7.

13 DiFiore JW, Fauza DO, Slavin R, Wilson JM. Experimental fetal tracheal ligation and congenital diaphragmatic hernia; A pulmonary vascular morphometric analysis. F Pediatr Surg 1995;30:917-24

14 Sylvester KG, Rasanen J, Kitano Y, Flake AW, Crombleholme TM, Adzick NS. Tracheal occlusion reverses the high impedence to flow in the fetal pulmonary circulation and normalizes its physiological response to oxygen at full term. F Pediatr Surg 1998;33:1071-5.

15 O'Toole SJ, Sharma A, Karamanoukian HL, Holm B, Azizkhan RG, Glick PL. Tracheal ligation does not correct the surfactant deficiency associated with congenital diaphragmatic hernia. f Pediatr Surg 1996;31:546-50.

16 Skarsgard ED, Meuli M, VanderWall KJ, Bealer JF, Adzick NS, Harrison MR. Fetal endoscopic tracheal occlusion ("Fetendo-PLUG") for congenital diaphragmatic hernia. F Pediatr Surg 1996;31:1335-8.

17 De Paepe ME, Papadakis K, Johnson BD, Luks FI. Fate of the type II pneumocyte following tracheal occlusion in utero: A time-course study in fetal sheep. Virchows Arch 1998;432:7-16.

18 O'Toole SJ, Karamanoukian HL, Irish MS, Sharma A, Holm BA, Glick PL. Tracheal ligation: The dark side of in utero congenital diaphragmatic hernia treatment. F Pediatr Surg 1997;32:407-10.

19 Piedboeuf B, Laberge J-M, Ghitulescu G, Gamache M, Petrov P, Belanger $S$, Chen M-F, Hashim E, Possmayer F. Deleterious effect of tracheal $\mathrm{S}$, Chen M-F, Hashim E, Possmayer F. Deleterious effect of tracheal
obstruction on type 2 pneumocytes in fetal sheep. Pediatr Res 1997; obstruction.

20 Flageole H, Evrard VA, Piedboeuf B, Laberge J-M, Lerut TE, Deprest JAM. The plug-unplug sequence: An important step to achieve type 2 pneumocyte maturation in the fetal lamb model. F Pediatr Surg 1998;33:299-303.

21 Keramidaris E, Hooper SB, Harding R. Effect of gestational age on the increase in fetal lung growth following tracheal ligation. Exp Lung Res 1996;22:283-98.

22 Papadakis K, Luks FI, De Paepe ME, Piasecki GJ, Wesselhoeft CW. Fetal lung growth after tracheal ligation is not solely a pressure phenomenon. $\mathcal{F}$ Pediatr Surg 1997;32:347-51.

23 Nobuhara KK, DiFiore JW, Ibla JC, et al. Insulin-like growth factor 1 gene expression in three models of accelerated lung growth. $\mathcal{F}$ Pediatr Surg 1998;33:1057-61.

24 Hooper SB, Han VKM, Harding R. Changes in lung expansion alter pulmonary DNA synthesis and IGF-II gene expression in fetal sheep. Am f Physiol 1993;265 L403-9.

25 Sundell HW, Gray ME, Serenius FS, Escobedo MB, Stahlman MT. Effects of epidermal growth factor on lung maturation in fetal lambs. Am f Pathol 1980;100:707-26.

26 Harrison MR, Adzick NS, Flake AW, et al. Correction of congenital diaphragmatic hernia in utero VIII: Response of the hypoplastic lung to tracheal occlusion. F Pediatr Surg 1996;31:1339-48.

27 Flake AW, Johnson MP, Treadwell M, et al. In utero treatment of right sided congenital diaphragmatic hernia by prenatal tracheal occlusion. $A m \mathcal{F}$ Obstet Gynecol 1996;174:489.

28 Van der Wall KJ, Skarsgard ED, Filly RA, Eckert J, Harrison MR. Fetendo clip; A fetal endoscopic tracheal clip procedure in a human fetus. $\mathcal{F}$ Pediatr Surg 1997;32:970-2.

29 Graf JL, Gibbs DL, Adzick NS, Harrison MR. Fetal hydrops after in utero tracheal occlusion. F Pediatr Sug 1997;32:214-16.

30 Greenholz SK. Congenital diaphragmatic hernia: An overview. Semin Pediatr Surg 1996;5:216-223.

31 Harrison MR, Adzick NS, Flake AW, et al. Correction of congenital diaphragmatic hernia in utero: VI. Hard-earned lessons. $\mathcal{F}$ Pediatr Surg 1993;28:1411-18. 